(2) Open Access Full Text Article

\title{
Expression and prognostic relevance of MET and phospho-BAD in non-small cell lung cancer
}

This article was published in the following Dove Press journal:

OncoTargets and Therapy

17 September 2013

Number of times this article has been viewed

\author{
Wenze Sun' \\ Ting $\mathrm{Ai}^{2}$ \\ Ying Gao' \\ Yingbing Zhang' \\ Jie Cui' \\ Liping Song' \\ 'Department of Radiation Oncology, \\ ${ }^{2}$ Department of Neonatology, First \\ Affiliated Hospital, Medical College \\ of Xi'an Jiaotong University, Xi'an, \\ People's Republic of China
}

Correspondence: Liping Song Department of Radiation Oncology, First Affiliated Hospital of Medical College of Xi'an Jiaotong University, 277 Yanta West Road, Yanta District, Xi'an 71006I, People's Republic of China Tel +860298532462I

Fax +860298532 4621

Email xaslp@126.com
Background: MET is involved in the progression of several types of human cancers, while phospho-BAD(Ser-136) is a key molecule in apoptosis and might be regulated by MET. The aim of this study was to investigate the correlation between altered expression of MET and phosphoBAD in non-small cell lung cancer (NSCLC) and their association with clinicopathologic parameters and overall survival.

Methods: MET and phospho-BAD(Ser-136) proteins were evaluated by immunohistochemical analysis in 183 paraffin-embedded specimens and were also assessed by Western blotting analysis in 12 frozen tumor tissue samples, which were representative examples of immunohistochemical staining.

Results: Positive expression of MET and phospho-BAD(Ser-136) occurred in $67.2 \%$ and $49.2 \%$ of the 183 cases of NSCLC, respectively. However, neither MET expression nor phosphoBAD(Ser-136) expression was associated with any clinicopathologic parameter. A significant correlation was found between MET and phospho-BAD(Ser-136) expression levels evaluated by immunohistochemistry $(r=0.268, P<0.001)$. Overexpression of MET was significantly associated with shortened overall survival in univariate analysis $(P<0.001)$. Moreover, patients with a MET+/phospho-BAD(Ser-136)+ phenotype had a poorer prognosis than others $(P<0.001)$. Multivariate Cox proportional hazard analysis confirmed that MET expression is a prognostic factor for NSCLC.

Conclusion: MET expression might be correlated with phospho-BAD(Ser-136) expression, and may be an adverse predictor for NSCLC. Activation of the MET/phospho-BAD(Ser-136) signaling pathway might play a role in the development and progression of NSCLC.

Keywords: MET, phospho-BAD, prognosis, non-small cell lung cancer

\section{Introduction}

Lung cancer is the leading cause of cancer-related death throughout the world, while $80 \%-85 \%$ of primary lung cancer cases are specifically non-small cell lung cancer (NSCLC). ${ }^{1}$ The prognosis of NSCLC cases is usually poor because of late diagnosis and therapeutic limitations. Therefore, exploration of new molecular markers involved in progression of NSCLC can facilitate effective targeted treatment and prognostic assessment. Based on advancement of the knowledge about the molecular mechanisms of NSCLC, much interest has focused recently on an aberrant MET signaling pathway in NSCLC.

MET, which is encoded by the MET gene, is the receptor with the highest affinity for hepatocyte growth factor/scatter factor. Hepatocyte growth factor/scatter factor binds to the MET receptor and results in autophosphorylation of several tyrosine 
residues within the intracellular region, leading to activation of downstream signaling pathways, such as phosphoinositide3-kinase (PI3K), Ras-Rac/Rho, Ras mitogen-activated protein kinase, and phospholipase $\mathrm{C}-\gamma{ }^{2}$ Thus, the activated hepatocyte growth factor/MET pathway promotes tumor growth, angiogenesis, and metastasis in several types of human cancers, including NSCLC, making it a promising research target for potential anticancer treatment. ${ }^{3-6}$

MET abnormalities occur frequently in NSCLC, including protein overexpression, gene mutation, and gene amplification. Although several clinical studies have revealed that MET protein is expressed in approximately $70 \%$ of adenocarcinoma and $40 \%$ of squamous cell carcinoma in lung cancer cases and overexpression of MET is associated with a poor prognosis in NSCLC patients, the clinicopathologic features and prognostic value of MET overexpression remains controversial..$^{7-9}$

One of the tumorigenic mechanisms responsible for development of NSCLC is evasion of apoptosis. ${ }^{10}$ Defects in regulation of apoptosis lead to tumorigenesis and resistance to chemotherapy in various cancer cells. ${ }^{11,12}$ Alterations in proapoptotic and antiapoptotic pathways are common in cancer cells, and regulation of apoptosis is a complicated process that involves a myriad of proteins. ${ }^{13}$ In particular, BAD, one of the death-promoting proteins in the Bcl-2 gene family, exerts its death-promoting effect by heterodimerizing with BCL$\mathrm{X}_{\mathrm{L}}$ and BCL-2 death antagonists in the mitochondria, and is tightly regulated by survival factors. ${ }^{14}$ Dephosphorylation activates BAD protein to initiate apoptosis, while phosphorylation of several serine residues (Ser-112 and Ser-136) will inactivate BAD to promote cell survival. ${ }^{15}$ Although phosphorylation of BAD has been shown to contribute to tumorigenesis and drug resistance, the clinical relevance and prognostic value of phospho-BAD protein expression in NSCLC remains unclear. Furthermore, studies have recently presented evidence that AKT, a serine/threonine protein kinase downstream of PI3K, can bind to and phosphorylate BAD at Ser-136 residues in vitro. ${ }^{16,17}$ Thus, activated hepatocyte growth factor/MET signaling may be linked to phosphorylation of BAD at the Ser-136 residual through the PI3K-AKT pathway and play a key role in regulation of cell survival in NSCLC. However, a combined analysis of MET and phospho-BAD abnormalities in NSCLC has never been reported, and this new insight of combining biomarkers might improve the clinical outcome of NSCLC.

In this study, we detected the expression of MET and phospho-BAD(Ser-136) using immunohistochemistry and Western blotting, and explored whether the expression level of MET correlated with phospho-BAD(Ser-136) in these patients. We also investigated their clinicopathologic and prognostic significance in NSCLC.

\section{Patients and methods Study population}

One hundred and eighty-three NSCLC patients who underwent tumor resection at the First Affiliated Hospital of Xi' an Jiaotong University from 2003 to 2010 were enrolled in the study. The patients included 141 males and 42 females aged 44-71 (mean 56.2) years. None of these patients received neoadjuvant chemotherapy before surgery. All patients were followed closely until June 30, 2012, and the mean duration of follow-up was $39.2 \pm 12.6$ months. Tumor histologic classification and differentiation were done according to the 1999 histologic classification standards of lung cancer published by the World Health Organization. TNM staging was carried out according to the 2004 guidelines of the National Comprehensive Cancer Network for NSCLC. Clinical and pathologic features of the patients enrolled in the study are shown in Table 1. The research was approved by the institutional ethics committee of First Affiliated Hospital of Medical College of Xi'an Jiaotong University. Written informed consent was obtained from each patient.

\section{Immunohistochemistry}

First, formalin-fixed and paraffin-embedded tissue sections (4 $\mu \mathrm{m})$ underwent deparaffinization and hydration. Antigen retrieval was done in buffer $(1 \mathrm{mmol} / \mathrm{L}$ EDTA/phosphatebuffered saline, $\mathrm{pH} 9.0$ ) at $98^{\circ} \mathrm{C}$ for 30 minutes in a water bath. Endogenous peroxide blocking was performed with $3 \%$ hydrogen peroxide for 10 minutes. Next, the slides were incubated with rabbit anti-MET antibody (1:200; Santa Cruz Biotechnology Inc, CA, USA) and rabbit antiphosphoBAD(Ser-136) antibody (1:200; Abcam, Cambridge, MA, USA) overnight at $4^{\circ} \mathrm{C}$. The stained sections were exposed to a 3,3-diaminobenzidine kit (Zhongshan Biotechnology Inc, Beijing, People's Republic of China) and finally counterstained with Mayer's hematoxylin. An irrelevant rabbit antiserum instead of primary antibodies served as the negative control.

\section{Immunohistochemical analysis}

The results of staining were evaluated by two independent pathologists who were blinded to the clinical data. Immunochemical scoring was based on both the percentage of positive cells and the intensity of staining on five randomly visual fields under the optical microscope. The intensity of staining 
Table I Association between MET and pBAD ${ }^{S 136}$ expression and combined status of MET/pBAD ${ }^{S 136}$ and clinicopathologic parameters

\begin{tabular}{|c|c|c|c|c|c|c|c|c|c|c|}
\hline \multirow[t]{2}{*}{ Variables } & \multirow[t]{2}{*}{ All } & \multicolumn{3}{|c|}{ MET protein expression } & \multicolumn{3}{|c|}{ pBAD $^{S 136}$ protein expression } & \multicolumn{3}{|c|}{$\begin{array}{l}\text { MET expression/pBAD } \\
\text { expression }\end{array}$} \\
\hline & & $-(\%)$ & $+(\%)$ & $P$ & $-(\%)$ & $+(\%)$ & $\mathbf{P}$ & $\begin{array}{l}\text { MET+l } \\
\text { pBAD }^{5136}+(\%)\end{array}$ & $\begin{array}{l}\text { Others } \\
\text { (\%) }\end{array}$ & $P$ \\
\hline All & 183 & $60(32.8)$ & $123(67.2)$ & & $93(50.8)$ & $90(49.2)$ & & $72(39.3)$ & III (60.7) & \\
\hline \multicolumn{11}{|l|}{ Sex } \\
\hline Male & $|4|$ & $48(34.0)$ & $93(66.0)$ & 0.634 & $75(53.2)$ & $66(46.8)$ & 0.317 & $51(36.2)$ & $90(63.8)$ & 0.153 \\
\hline Female & 42 & $12(28.6)$ & $30(7 \mid .4)$ & & $18(42.9)$ & $24(57.1)$ & & $21(50.0)$ & $21(50.0)$ & \\
\hline \multicolumn{11}{|l|}{ Age (years) } \\
\hline$<60$ & 118 & $36(30.5)$ & $82(69.5)$ & 0.471 & $63(53.4)$ & $55(46.6)$ & 0.434 & $46(39.0)$ & $72(61.0)$ & 1.000 \\
\hline$\geq 60$ & 65 & $24(36.9)$ & $41(63.1)$ & & $30(46.2)$ & $35(53.8)$ & & $26(40.0)$ & $39(60.0)$ & \\
\hline \multicolumn{11}{|l|}{ Smoking history } \\
\hline Yes & 117 & $39(33.3)$ & $78(66.7)$ & 0.964 & $57(48.7)$ & $60(5 \mid .3)$ & 0.546 & $45(38.5)$ & $72(6 \mid .5)$ & 0.867 \\
\hline No & 66 & $21(31.8)$ & $45(68.2)$ & & $36(54.5)$ & $30(45.5)$ & & $27(40.9)$ & $39(59.1)$ & \\
\hline \multicolumn{11}{|l|}{ Histology } \\
\hline $\mathrm{AC}$ & 84 & $24(28.6)$ & 60 (7I.4) & 0.337 & $42(50.0)$ & $42(50.0)$ & 0.955 & $36(42.9)$ & $48(57.1)$ & 0.457 \\
\hline $\mathrm{SCC}$ & 99 & $36(36.4)$ & $63(63.6)$ & & $5 I(51.5)$ & $48(48.5)$ & & $36(36.4)$ & $63(63.6)$ & \\
\hline \multicolumn{11}{|l|}{ Differentiation } \\
\hline $\begin{array}{l}\text { Well } \\
\text { differentiated }\end{array}$ & 119 & $42(35.3)$ & 77 (64.7) & 0.412 & $60(50.4)$ & $59(49.6)$ & 1.000 & $47(39.5)$ & $72(60.5)$ & 1.000 \\
\hline $\begin{array}{l}\text { Poorly } \\
\text { differentiated }\end{array}$ & 64 & $18(28.1)$ & 46 (7I.9) & & $33(51.6)$ & $31(48.4)$ & & $25(39.1)$ & 39 (60.9) & \\
\hline \multicolumn{11}{|l|}{ T-status } \\
\hline TI-2 & 144 & $45(3 \mid .3)$ & $99(68.7)$ & 0.510 & $75(52.1)$ & 69 (47.9) & 0.634 & $57(39.6)$ & $87(60.4)$ & 1.000 \\
\hline T3-4 & 39 & $15(38.5)$ & $24(61.5)$ & & $18(46.2)$ & $21(53.8)$ & & $15(38.5)$ & $24(61.5)$ & \\
\hline \multicolumn{11}{|c|}{ Lymph node metastasis } \\
\hline No & 142 & $47(33.1)$ & $95(66.9)$ & 1.000 & $7 \mid(50.0)$ & 7II (50.0) & 0.814 & $59(4 \mid .5)$ & $83(58.5)$ & 0.340 \\
\hline Yes & 41 & $13(3 \mid .7)$ & $28(68.3)$ & & $22(53.7)$ & $19(46.3)$ & & $13(3 \mid .7)$ & $28(68.3)$ & \\
\hline \multicolumn{11}{|l|}{ TNM stage } \\
\hline$I+I I$ & 135 & $48(35.6)$ & $87(64.4)$ & 0.246 & $69(51.1)$ & $66(48.9)$ & 1.000 & $54(40.0)$ & $8 I(60.0)$ & 0.895 \\
\hline III + IV & 48 & $12(25.0)$ & $36(75.0)$ & & $24(50.0)$ & $24(50.0)$ & & $18(62.5)$ & $30(37.5)$ & \\
\hline
\end{tabular}

Abbreviations: $\mathrm{PBAD}^{\mathrm{s} 136}$, phospho-BAD(Ser-136); AC, adenocarcinoma; SCC, squamous cell carcinoma; TNM, tumor-node-metastasis.

was scored as: 0, without stain; 1, straw yellow; 2, brown; and 3 , dark brown. According to the percentage of tumor cells stained positive, extent of staining was scored as: $0,0 \% ; 1$, $1 \%-25 \% ; 2,26 \%-50 \% ; 3,51 \%-75 \%$; or $4,76 \%-100 \%$. The final score was the sum of the two scores. Tumor tissues with a final score $\leq 3$ were considered as negative, while those with a final score $>3$ were considered as positive.

\section{Western blot analysis}

An immunoblot assay was done on 12 cases that were assessed by immunohistochemistry and considered to be representative staining examples of MET and phospho-BAD(Ser-136) expression. Total protein was extracted from the fresh frozen tissues using a whole protein extraction kit (KeyGEN, Nanjing, People's Republic of China) according to the manufacturer's instructions. Concentration of protein were determined by using the BCA Protein Assay Reagent (Thermo Scientific, Rockford, IL, USA). Equal amounts of total protein from different samples were electrophoresed on a $10 \%$ sodium dodecyl sulfate-polyacrylamide gel and transferred to nitrocellulose membrane using standard protocols. Rabbit anti-MET (1:200; Santa Cruz Biotechnology Inc), rabbit antiphosphoBAD(Ser-136) (1:200; Abcam) and rabbit anti-glyceraldehyde 3-phosphate dehydrogenase (GAPDH, 1:3000; Proteintech Group, Chicago, IL, USA) antibodies and secondary antibody (1:5000; Cell Signaling Technology, Beverly, MA, USA) were used to detect MET, phospho-BAD(Ser-136), and GAPDH proteins, respectively. Proteins were detected by enhanced chemiluminescence (Thermo Scientific).

\section{Statistical analysis}

Statistical Package for the Social Sciences version 17.0 software (SPSS Inc, Chicago, IL, USA) was used for the statistical analysis. The association between clinical characteristics and MET and phospho-BAD(Ser-136) expression status was determined using the Chi-squared $\left(\chi^{2}\right)$ test. Spearman's rank correlation analysis was used to analyze the association between MET and phospho-BAD(Ser-136) expression levels. Overall survival curves were calculated using the Kaplan-Meier method and compared by log-rank test. Multivariate analysis 
was performed using a Cox proportional hazards regression model analysis. A value of $P<0.05$ was considered to be statistically significant.

\section{Results}

Expression of MET and phosphoBAD(Ser-136) in NSCLC by immunohistochemistry and their association with clinicopathologic variables

In this study, the aberrant expression of MET and phospho-BAD(Ser-136) in NSCLC tissue specimens was first evaluated by immunohistochemical analysis. MET protein was primarily localized in the cytoplasm or on the cell membrane of tumor cells, while phospho-BAD(Ser-136) protein was found predominantly in the cytoplasm (Figures 1 and 2). Immunohistochemical staining analysis showed that MET was expressed in $67.2 \%$ (123/183) of these NSCLC cases, includ-
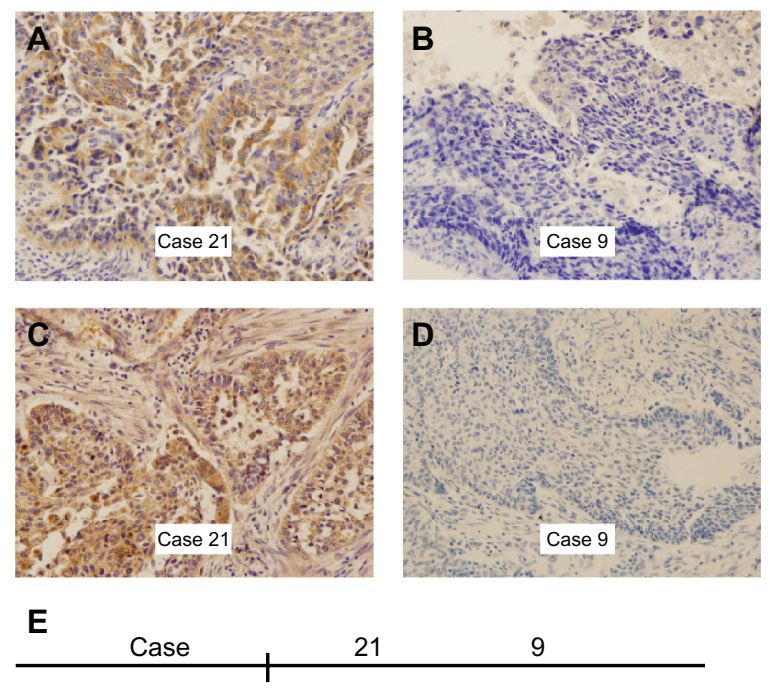

pBAD(S-136)

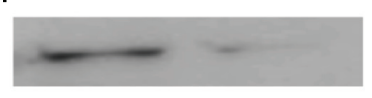

MET

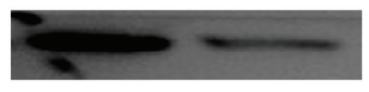

GAPDH

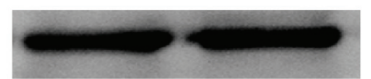

Figure I Immunohistochemical staining and Western blotting for MET and phospho-BAD(Ser-136) in squamous cell carcinoma of the lung. (A and $\mathbf{B}$ ) Positive and negative staining of MET in squamous cell carcinoma. Case 21 shows strong cytoplasmic/membrane staining, whereas case 9 shows only weak cytoplasmic staining. (C and D) Positive and negative staining of phospho-BAD(Ser-136) in squamous cell carcinoma. Case 2I shows strong cytoplasmic staining, whereas case 9 shows only weak cytoplasmic staining. (E) Western blotting with MET and phospho-BAD(Ser-136) expression in cases with squamous cell carcinoma of the lung, indicating increased phospho-BAD(Ser-136) detection in the case with positive expression of MET by immunohistochemistry. Magnification $\times 400$.
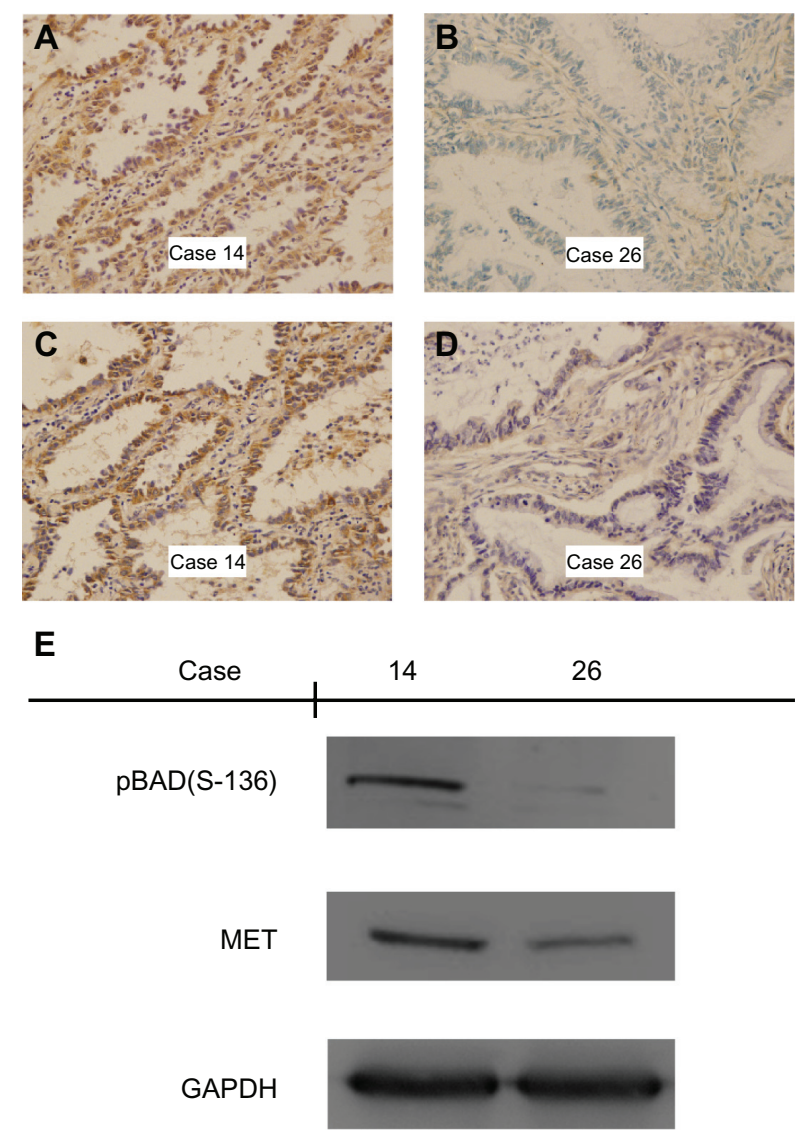

Figure 2 Immunohistochemical staining and Western blotting for MET and phospho$\mathrm{BAD}($ Ser-136) in adenocarcinoma of the lung. (A and B) Positive and negative staining of MET in adenocarcinoma. Case 14 shows strong cytoplasmic/membrane staining, whereas case 26 shows only weak cytoplasmic staining. (C and D) Positive and negative staining of phospho-BAD(Ser-136) in adenocarcinoma. Case 14 shows strong cytoplasmic staining, whereas case 26 shows only weak cytoplasmic staining. (E) Western blotting with MET and phospho-BAD(Ser-136) expression in cases with adenocarcinoma of the lung, indicating increased phospho-BAD(Ser-I36) detection in the case with positive expression of MET by immunohistochemistry. Magnification $\times 400$.

ing 60 adenocarcinomas and 63 squamous cell carcinomas. Phospho-BAD(Ser-136) was expressed in $49.2 \%(90 / 183)$ of these NSCLC cases, including 42 adenocarcinomas and 48 squamous cell carcinomas. However, neither MET nor phospho-BAD(Ser-136) protein was associated with any clinicopathologic characteristics, including sex, age, smoking history, histology, differentiation, T-status, lymph node metastasis, or TNM stage. Detailed results are shown in Table 1.

\section{Association of MET expression level with phospho-BAD(Ser-136) expression in NSCLC by immunohistochemistry and Western blotting}

We next investigated the association between MET expression and phospho-BAD(Ser-136) expression in NSCLC by immunohistochemistry, and found there was 
a significant association between MET and phosphoBAD(Ser-136) expression levels (Table 2, Spearman's $r=0.268, P<0.001)$. Of the 123 tumor tissues with METpositive expression, 72 cases $(72 / 123,58.5 \%)$ also displayed phospho-BAD(Ser-136)-positive expression. According to the expression status of MET and phospho-BAD(Ser-136), all NSCLC patients were classified into two groups, ie, $\mathrm{MET}+/$ phospho-BAD(Ser-136)+(39.3\%, 72/183) and others $(60.7 \%, 111 / 183)$. The correlation between the MET+/ phospho-BAD(Ser-136)+ phenotype and clinicopathologic variables was also analyzed, as shown in Table 1.

To confirm that MET expression was significantly associated with phospho-BAD(Ser-136) expression, as determined by immunohistochemistry, protein from frozen tissues of 12 representative examples of MET and phospho-BAD(Ser-136) staining was extracted. Western blotting analysis showed that high levels of phospho-BAD(Ser-136) were observed only in the samples with high expression of MET by immunohistochemistry, while phospho-BAD(Ser-136) was correspondingly downregulated in all the samples with low expression of MET by immunohistochemistry (Figures 1 and 2).

\section{Survival analysis}

The correlations between MET and phospho-BAD(Ser-136) expression level and prognosis in NSCLC patients were analyzed by the Kaplan-Meier method. As shown in Figure 3 and Table 3, patients with MET-positive expression had a poor prognosis in NSCLC $(P<0.001$; Figure 3A). The median survival time for MET-positive and MET-negative expression was 38.9 and 60.3 months, respectively. However, expression of phospho$\mathrm{BAD}($ Ser-136) was not significantly associated with overall survival ( $P=0.310$; Figure $3 \mathrm{~B})$. When considering overall survival and combined status of MET and phospho-BAD(Ser-136) expression, we found that the MET+/phospho-BAD(Ser-136)+ phenotype was associated with shorter overall survival than the others $(P<0.001$; Figure $3 \mathrm{C})$.

Next, to test whether MET expression was an independent prognostic factor in NSCLC patients, we performed a multivariate survival analysis. Although in univariate analysis,

Table 2 Association between MET and $\mathrm{PBAD}^{\mathrm{s} 136}$ expression in non-small cell lung cancer tissues

\begin{tabular}{llllll}
\hline Variable & Total & \multicolumn{2}{l}{ pBAD ${ }^{\text {s136 }}$ protein } & & \\
\cline { 3 - 6 } & & Negative & Positive & $\boldsymbol{r}$ & $\boldsymbol{P}$ \\
\hline MET protein & & & & 0.268 & $<0.001$ \\
Negative & 60 & 42 & 18 & & \\
Positive & 123 & 51 & 72 & & \\
\hline
\end{tabular}

Abbreviation: $\mathrm{pBAD}^{s 136}$, phospho-BAD(Ser-136).
T-status $(P=0.031)$, TNM stage $(P=0.001)$, and MET expression $(P<0.001)$, as well as combined expression status of MET+/phospho-BAD $($ Ser-136 $)+(P<0.001)$ were associated with overall survival, in multivariate analysis, only expression of MET protein (hazard ratio 4.321, 95\% confidence interval 2.508-7.446, $P=0.001$ ), and TNM stage (hazard ratio 2.276, $95 \%$ confidence interval 1.305-3.967, $P<0.004$ ) were independent prognostic factors in our NSCLC patients. Detailed data are shown in Tables 3 and 4.

\section{Discussion}

In this study, we analyzed the expression of MET and phospho-BAD(Ser-136) in NSCLC for the first time. MET and phospho-BAD(Ser-136) proteins were expressed in $67.2 \%$ and $49.2 \%$ of the study population of NSCLC patients, respectively, and there was a significant association between MET and phospho-BAD(Ser-136) expression levels on both immunohistochemistry and Western blotting. MET overexpression was associated with poor survival and was an independent indicator of the prognosis, whereas expression of phospho-BAD(Ser-136) was not associated with overall survival.

MET, a high-affinity receptor for hepatocyte growth factor, is usually considered as an oncogene. ${ }^{18}$ Hepatocyte growth factor binds to MET receptor and undergoes phosphorylation on intracellular tyrosine residues, leading to activation of some downstream signaling events. The hepatocyte growth factor/MET pathway has multiple biological functions, including cell proliferation, motility, angiogenesis, and morphogenesis. Although many human cancers show overexpression of MET, the role of MET overexpression in the development and progression of NSCLC is not fully understood. In NSCLC, MET protein is reported to be overexpressed in tumor tissues relative to adjacent tissues, and expression rates range between $24.0 \%$ and $81.0 \% .{ }^{19-22}$ In the current study, MET expression positivity was observed in $67.2 \%(123 / 183)$ of resected NSCLC tissues, within the range of expression rates previously reported, but was not associated with any clinicopathologic characteristics, including sex, age, smoking history, histology, differentiation, T-status, lymph node metastasis, or TNM stage. Some clinical studies have shown that MET expression occurs more commonly in adenocarcinoma of the lung than in squamous cell carcinoma. ${ }^{7,19,22}$ However, consistent with our study, Masuya et al detected MET protein in 188 NSCLC patients by immunohistochemistry and also failed to show any association between positivity of MET expression and histology. ${ }^{20}$ 
A

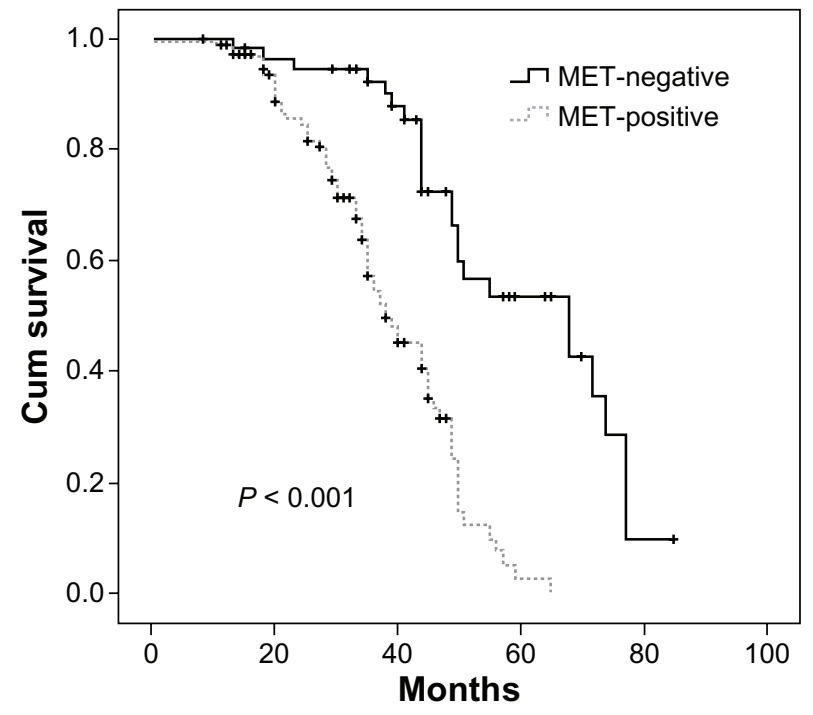

B

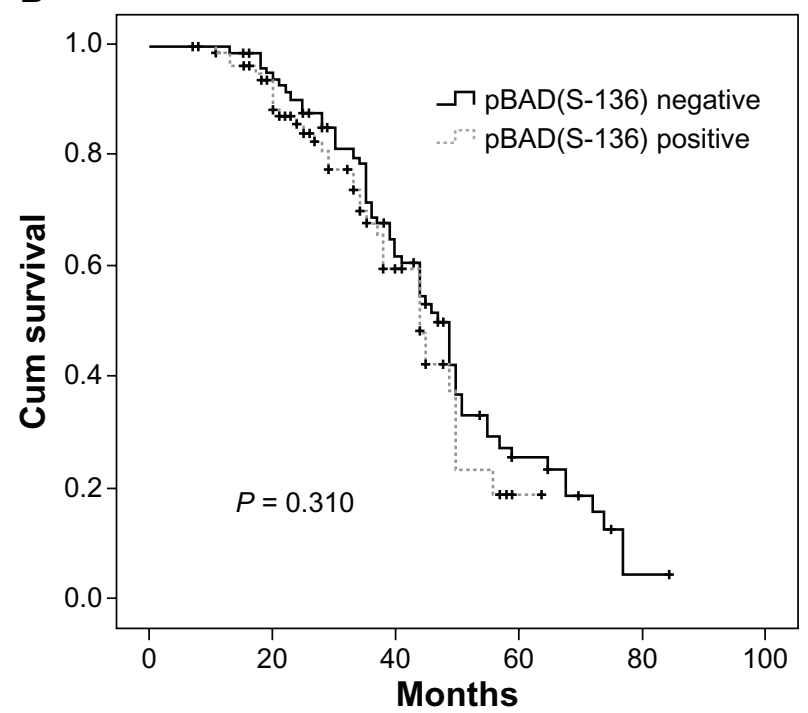

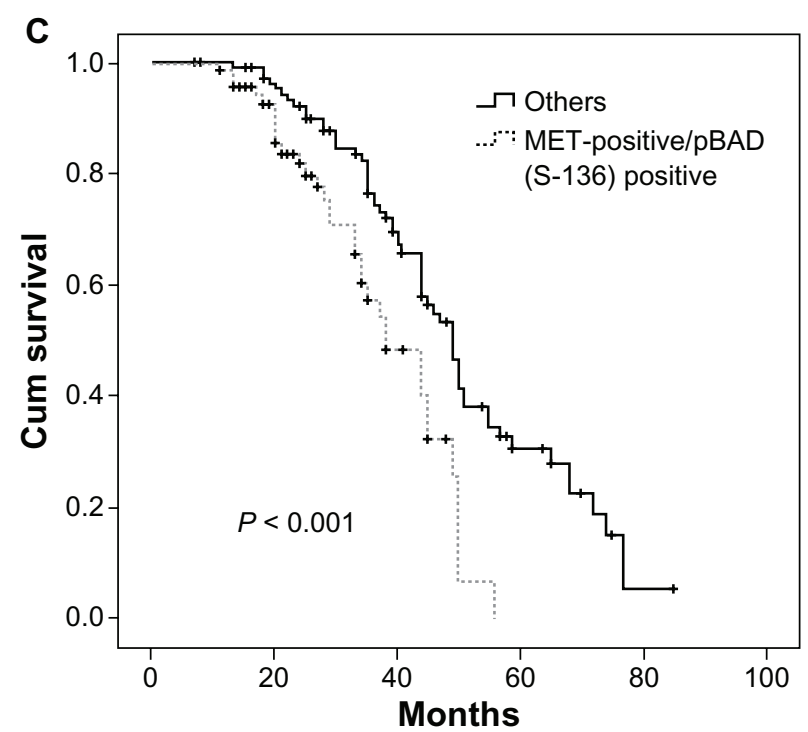

Figure 3 Kaplan-Meier survival analysis. (A) Overall survival curves for patients with MET-positive and MET-negative expression $(P<0.00 \mathrm{I})$. (B) Overall survival curves for patients with phospho-BAD(Ser-136)-positive and phospho-BAD(Ser-136)-negative expression $(P=0.310)$. (C) Overall survival curves for patients with MET+/phospho$\mathrm{BAD}($ Ser-136)+ and other phenotypes $(P<0.00 \mathrm{I})$.

Although some studies have confirmed that overexpression of MET is associated with poor survival, the prognostic value of MET expression in NSCLC is debatable. The study reported by Masuya et al showed shortened overall survival in cases with MET-positive expression. ${ }^{20}$ Similarly, Ichimura et al analyzed MET expression in 104 NSCLCs using immunohistochemistry and demonstrated a tendency for worse survival in patients with MET-positive expression. ${ }^{7}$ Consistent with these data, our study showed that MET-positive expression was associated with poor overall survival in patients with NSCLC. Further, multivariate analysis revealed MET-positive expression to be an adverse prognostic factor that did not correlate with any clinicopathologic characteristics, but the clinical sequence by which MET overexpression leads to poor prognosis remains unclear. Recently, MET overexpression has been reported to contribute to development of acquired chemoresistance and radioresistance via multiple downstream pathways in several types of cancer cells. ${ }^{23-26}$ Thus, MET might be involved in chemoresistance or radioresistance in NSCLC and linked to a poor prognosis. In contrast, Tsuta et al and Dziadziuszko et al reported that expression of MET protein was not associated with survival. ${ }^{22,27}$ The discrepancy may be due to different 
Table 3 Univariate analysis of clinicopathologic variables for overall survival

\begin{tabular}{|c|c|c|c|c|}
\hline \multirow[t]{2}{*}{ Variables } & \multirow[t]{2}{*}{ Total } & \multicolumn{2}{|c|}{ Overall survival } & \multirow[t]{2}{*}{$P$} \\
\hline & & Median \pm SE & $95 \% \mathrm{Cl}$ & \\
\hline \multicolumn{5}{|l|}{ Sex } \\
\hline Male & 141 & $46.725 \pm 1.827$ & $43.145-50.305$ & 0.836 \\
\hline Female & 42 & $49.064 \pm 4.641$ & $39.967-58.161$ & \\
\hline \multicolumn{5}{|l|}{ Age (years) } \\
\hline$<60$ & 118 & $45.019 \pm 2.041$ & $41.020-49.019$ & 0.112 \\
\hline$\geq 60$ & 65 & $52.389 \pm 3.549$ & $45.433-59.344$ & \\
\hline \multicolumn{5}{|c|}{ Smoking history } \\
\hline Yes & 117 & $46.38 \mathrm{I} \pm 2.212$ & $42.045-50.716$ & 0.627 \\
\hline No & 66 & $48.333 \pm 2.806$ & $42.832-53.833$ & \\
\hline \multicolumn{5}{|l|}{ Histology } \\
\hline$A C$ & 84 & $45.265 \pm 2.795$ & $39.786-50.743$ & 0.424 \\
\hline $\mathrm{scC}$ & 99 & $48.254 \pm 2.256$ & $43.832-52.677$ & \\
\hline \multicolumn{5}{|c|}{ Differentiation } \\
\hline $\begin{array}{l}\text { Well } \\
\text { differentia }\end{array}$ & 119 & $49.118 \pm 2.199$ & $44.809-53.428$ & 0.084 \\
\hline $\begin{array}{l}\text { Poorly } \\
\text { differentia }\end{array}$ & 64 & $40.759 \pm 1.874$ & $37.086-44.432$ & \\
\hline \multicolumn{5}{|l|}{ T-status } \\
\hline TI-2 & 144 & $48.539 \pm 1.946$ & $44.725-52.353$ & 0.031 \\
\hline T3-4 & 39 & $38.546 \pm 2.591$ & $33.467-43.624$ & \\
\hline \multicolumn{5}{|c|}{ Lymph node metastasis } \\
\hline No & 142 & $46.687 \pm 1.915$ & $42.934-50.439$ & 0.745 \\
\hline Yes & 41 & $44.818 \pm 2.613$ & $36.695-49.940$ & \\
\hline \multicolumn{5}{|l|}{ TNM stage } \\
\hline$I+I I$ & 135 & $49.005 \pm 1.913$ & $45.256-52.754$ & 0.001 \\
\hline $\mathrm{III}+\mathrm{IV}$ & 48 & $34.520 \pm 1.999$ & $30.602-38.438$ & \\
\hline \multicolumn{5}{|c|}{ MET expression } \\
\hline Negative & 60 & $60.289 \pm 2.967$ & $54.475-66.104$ & $<0.001$ \\
\hline Positive & 123 & $38.889 \pm 1.37 \mid$ & $36.202-41.577$ & \\
\hline \multicolumn{5}{|c|}{ pBAD ${ }^{5136}$ expression } \\
\hline Negative & 93 & $48.510 \pm 2.237$ & $44.126-52.894$ & 0.310 \\
\hline Positive & 90 & $42.972 \pm 2.043$ & $38.967-46.977$ & \\
\hline \multicolumn{5}{|c|}{ MET expression/pBAD ${ }^{5136}$ expression } \\
\hline $\begin{array}{l}\text { MET+l } \\
\text { pBAD }^{\text {S136+ }}\end{array}$ & 72 & $37.856 \pm 1.812$ & $34.305-41.407$ & $<0.001$ \\
\hline Others & 111 & $50.739 \pm 2.145$ & $46.534-54.944$ & \\
\hline
\end{tabular}

Abbreviations: AC, adenocarcinoma; SCC, squamous cell carcinoma; TNM,

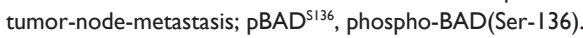

patient populations, antibodies, methods used, or even different scoring systems.

BAD is a distant member of the BCL-2 family (critical regulators of cell death in mammalian cells). The function of this proapoptotic molecule is regulated by phosphorylation of two sites, Ser-112 and Ser-136, which is mediated by the serine/threonine protein kinase Akt-1/PKB, downstream of PI3K ${ }^{28}$ Phosphorylation at either site results in loss of the ability of BAD to heterodimerize with the survival proteins, BCL-XL or BCL-2. Further research has shown that BAD abnormalities contribute to tumorigenesis and resistance to chemotherapy in some malignancies. Ranger et al showed
Table 4 Multivariate analysis of clinicopathologic variables for overall survival

\begin{tabular}{llll}
\hline Variables & \multicolumn{2}{l}{ Overall survival } & P \\
\cline { 2 - 3 } & Hazard ratio & $\mathbf{9 5 \%} \mathbf{~ C l ~}$ & \\
\hline $\begin{array}{l}\text { TNM stage } \\
\text { III + IV versus I + II }\end{array}$ & 2.276 & $1.305-3.967$ & 0.004 \\
$\begin{array}{l}\text { MET expression } \\
\quad \text { Positive versus negative }\end{array}$ & 4.32 I & $2.508-7.446$ & $<0.00$ I \\
\hline \multicolumn{2}{l}{ Abbreviations: Cl, confidence interval; TNM, tumor-node-metastasis. } &
\end{tabular}

that BAD-deficient mice are prone to develop leukemia/ lymphoma. ${ }^{12}$ Gilmore et al found that a primary culture of BAD-/-mammary cancer cells was no longer sensitive to gefitinib-induced apoptosis. ${ }^{11}$ Huang et al reported that the BAD expression level decreased significantly in NSCLC, and loss of BAD independently predicted a poor prognosis, especially in smokers. ${ }^{29}$ BAD was also observed to be a prognostic variable for stage II and III colon cancer and breast cancer patients. ${ }^{30,31}$ However, few reported studies have assessed the clinical relevance and prognostic value of phospho-BAD(Ser-136) expression.

The present study found that phospho-BAD(Ser-136) expression was not associated with any clinicopathologic characteristics. Interestingly, our study found that phosphoBAD(Ser-136) expression was significantly associated with MET expression by immunohistochemistry. Moreover, Western blotting in 12 representative NSCLC tissues confirmed increased phospho-BAD(Ser-136) detection only in cases with a high level of MET expression, while phospho-BAD(Ser-136) was correspondingly downregulated in all cases with a low level of MET expression. These data indicate that MET overexpression could upregulate expression of phospho-BAD(Ser-136), although the underlying molecular mechanism remains to be clarified. METassociated downstream pathways, such as PI3K/AKT, may be responsible.

Although the median survival time for patients with positive phospho-BAD(Ser-136) expression (43 months) was shorter than for patients with negative phospho-BAD(Ser-136) expression (49 months), there was no significant association between the expression level of phospho-BAD(Ser-136) and overall survival. Similarly, Cartron et al detected phospho$\mathrm{BAD}$ (Ser-136) in glioblastoma multiforme tumors using Western blotting and enzyme-linked immunosorbent assay and found no association between the expression level of phospho-BAD(Ser-136) and overall survival. ${ }^{32}$ A possible reason for this may be the presence of many other factors affecting apoptosis in NSCLC. 
The present study shows that the expression level of MET is significantly correlated with that of phospho-BAD(Ser-136) and is a negative prognostic factor in multivariate analysis. We investigated the correlation between the combined status of MET and phospho-BAD(Ser-136) expression and overall survival and found that patients with the MET+/phosphoBAD(Ser-136)+ phenotype had poorer overall survival than others at the univariate level. However, this was not an independent prognostic factor in multivariate analysis. This may be because a number of signaling pathways are activated by MET in the progression of NSCLC, except for the MET/ phospho-BAD(Ser-136) pathway. Therefore, the current data indicate that MET/phospho-BAD(Ser-136) pathway might play a role in the progression of NSCLC, but not necessarily a dominant one. Further research using a larger sample size is warranted to confirm our data.

Overall, the current study suggests that there is a significant positive correlation between expression of MET and that of phospho-BAD(Ser-136). MET overexpression was shown to be an adverse prognostic marker for patients with NSCLC. Therefore, an activated MET/phospho-BAD(Ser-136) pathway might play a role in the development and progression of NSCLC.

\section{Acknowledgments}

This study was supported in part by grants from the National Natural Science Foundation of China (81301937), Nature Science Foundation of Shaanxi Province of China (2011JM4037), the International Cooperation Foundation of Shaanxi Province of China (2013KW-27-03), and the Foundation of the First Affliated Hospital of Medical College of Xi' an Jiaotong University (2010YK3).

\section{Disclosure}

The authors declare that no conflict of interest exists in this work.

\section{References}

1. Jemal A, Siegel R, Ward E, et al. Cancer statistics. CA Cancer J Clin. 2006;56(2):106-130.

2. Birchmeier C, Birchmeier W, Gherardi E, Vande Woude GF. Met, metastasis, motility and more. Nat Rev Mol Cell Biol. 2003;4(12):915-925.

3. Comoglio PM, Boccaccio C. Scatter factors and invasive growth. Semin Cancer Biol. 2001;11(2):153-165.

4. Trusolino L, Comoglio PM. Scatter-factor and semaphorin receptors: cell signalling for invasive growth. Nat Rev. 2002;2(4):289-300.

5. Ma PC, Maulik G, Christensen J, Salgia R. c-Met: structure, functions and potential for therapeutic inhibition. Cancer Metastasis Rev. 2003;22(4): 309-325.

6. Cipriani NA, Abidoye OO, Vokes E, Salgia R. MET as a target for treatment of chest tumors. Lung Cancer. 2009;63(2):169-179.

7. Ichimura E, Maeshima A, Nakajima T, Nakamura T. Expression of c-met/ HGF receptor in human non-small cell lung carcinomas in vitro and in vivo and its prognostic significance. Jpn J Cancer Res. 1996;87(10):1063-1069.
8. Ma PC, Jagadeeswaran R, Jagadeesh S, et al. Functional expression and mutations of c-Met and its therapeutic inhibition with SU11274 and small interfering RNA in non-small cell lung cancer. Cancer Res. 2005;65(4):1479-1488.

9. Nakamura Y, Niki T, Goto A, et al. c-Met activation in lung adenocarcinoma tissues: an immunohistochemical analysis. Cancer Sci. 2007;98(7):1006-1013.

10. Han SW, Roman J. Targeting apoptotic signaling pathways in human lung cancer. Curr Cancer Drug Targets. 2010;10(6):566-574.

11. Gilmore AP, Valentijn AJ, Wang P, et al. Activation of BAD by therapeutic inhibition of epidermal growth factor receptor and transactivation by insulin-like growth factor receptor. J Biol Chem. 2002;277(31):27643-27650.

12. Ranger AM, Zha J, Harada H, et al. Bad-deficient mice develop diffuse large B cell lymphoma. Proc Natl Acad Sci U SA. 2003;100(16): 9324-9329.

13. Maiti D, Bhattacharyya A, Basu J. Lipoarabinomannan from Mycobacterium tuberculosis promotes macrophage survival by phosphorylating Bad through a phosphatidylinositol 3-kinase/Akt pathway. J Biol Chem. 2001;276(1):329-333.

14. Downward J. How BAD phosphorylation is good for survival. Nat Cell Biol. 1999;1(2):E33-E35.

15. Kuroda J, Taniwaki M. Involvement of BH3-only proteins in hematologic malignancies. Crit Rev Oncol Hematol. 2009;71(2):89-101.

16. Maulik G, Madhiwala P, Brooks S, et al. Activated c-Met signals through PI3K with dramatic effects on cytoskeletal functions in small cell lung cancer. J Cell Mol Med. 2002;6(4):539-553.

17. Kijima T, Maulik G, Ma PC, Madhiwala P, Schaefer E, Salgia R. Fibronectin enhances viability and alters cytoskeletal functions (with effects on the phosphatidylinositol 3-kinase pathway) in small cell lung cancer. J Cell Mol Med. 2003;7(2):157-164.

18. Cooper CS, Park M, Blair DG, et al. Molecular cloning of a new transforming gene from a chemically transformed human cell line. Nature. 1984;311(5981):29-33.

19. Tsao MS, Liu N, Chen JR, et al. Differential expression of MET/ hepatocyte growth factor receptor in subtypes of non-small cell lung cancers. Lung Cancer. 1998;20(1):1-16.

20. Masuya D, Huang C, Liu D, et al. The tumour-stromal interaction between intratumoral c-Met and stromal hepatocyte growth factor associated with tumour growth and prognosis in non-small-cell lung cancer patients. Br J Cancer. 2004;90(8):1555-1562.

21. Shibata T, Uryu S, Kokubu A, et al. Genetic classification of lung adenocarcinoma based on array-based comparative genomic hybridization analysis: its association with clinicopathologic features. Clin Cancer Res. 2005;11(17):6177-6185.

22. Tsuta K, Kozu Y, Mimae T, et al. c-MET/phospho-MET protein expression and MET gene copy number in non-small cell lung carcinomas. J Thorac Oncol. 2012;7(2):331-339.

23. Bowers DC, Fan S, Walter KA, et al. Scatter factor/hepatocyte growth factor protects against cytotoxic death in human glioblastoma via phosphatidylinositol 3-kinase- and AKT-dependent pathways. Cancer Res. 2000;60(15):4277-4283.

24. Jankowski K, Kucia M, Wysoczynski M, et al. Both hepatocyte growth factor (HGF) and stromal-derived factor-1 regulate the metastatic behavior of human rhabdomyosarcoma cells, but only HGF enhances their resistance to radiochemotherapy. Cancer Res. 2003;63(22): 7926-7935.

25. De Bacco F, Luraghi P, Medico E, et al. Induction of MET by ionizing radiation and its role in radioresistance and invasive growth of cancer. J Natl Cancer Inst. 2011;103(8):645-661.

26. Lal B, Xia S, Abounader R, Laterra J. Targeting the c-Met pathway potentiates glioblastoma responses to gamma-radiation. Clin Cancer Res. 2005;11(12):4479-4486.

27. Dziadziuszko R, Wynes MW, Singh S, et al. Correlation between MET gene copy number by silver in situ hybridization and protein expression by immunohistochemistry in non-small cell lung cancer. J Thorac Oncol. 2012;7(2):340-347. 
28. Datta SR, Dudek H, Tao X, et al. Akt phosphorylation of BAD couples survival signals to the cell-intrinsic death machinery. Cell. 1997;91(2): 231-241.

29. Huang Y, Liu D, Chen B, et al. Loss of Bad expression confers poor prognosis in non-small cell lung cancer. Med Oncol. 2012;29(3): 1648-1655.

30. Sinicrope FA, Rego RL, Foster NR, et al. Proapoptotic Bad and Bid protein expression predict survival in stages II and III colon cancers. Clin Cancer Res. 2008;14(13):4128-4133.
31. Seow HF, Yip WK, Loh HW, Ithnin H, Por P, Rohaizak M. Immunohistochemical detection of phospho-Akt, phospho-BAD, HER2 and oestrogen receptors alpha and beta in Malaysian breast cancer patients. Pathol Oncol Res. 2011;16(2):239-248.

32. Cartron PF, Loussouarn D, Campone M, Martin SA, Vallette FM. Prognostic impact of the expression/phosphorylation of the BH3-only proteins of the BCL-2 family in glioblastoma multiforme. Cell Death Dis. 2012;3:e421.

\section{Publish your work in this journal}

OncoTargets and Therapy is an international, peer-reviewed, open access journal focusing on the pathological basis of all cancers, potential targets for therapy and treatment protocols employed to improve the management of cancer patients. The journal also focuses on the impact of management programs and new therapeutic agents and protocols on

\section{Dovepress}

patient perspectives such as quality of life, adherence and satisfaction. The manuscript management system is completely online and includes a very quick and fair peer-review system, which is all easy to use. Visit http://www.dovepress.com/testimonials.php to read real quotes from published authors.

Submit your manuscript here: http://www.dovepress.com/oncotargets-and-therapy-journal 